\title{
Effects of fretting wear process on fatigue crack propagation and life assessment
}

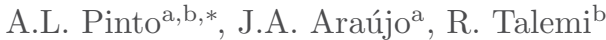 \\ ${ }^{a}$ Department of Mechanical Engineering, University of Brasilia, 70910-900 Brasilia, DF, \\ Brazil \\ ${ }^{b}$ Department of Materials Engineering, KU Leuven, 3001 Leuven, Belgium
}

\begin{abstract}
This paper proposes a new methodology for fretting fatigue life assessment. It uses a combination of multiaxial fatigue criteria, the theory of critical distances and a node-displacement wear algorithm to account for the initiation life under fretting. Further, the extended finite element method is considered to compute the propagation life. A new method is also introduced to predict the crack propagation path under nonproportional loading conditions. To validate the analysis, available fretting fatigue data using an Al 2024-T3 alloy was considered. All the total lives estimated by the proposed approach fell within a scatter band 2, with an error between $11 \%$ and $-39 \%$. An analysis of the energy dissipated on the contact surface was performed and showed that for certain cases the inclusion of wear in the modelling of the problem is indeed essential to obtain more accurate fretting fatigue life assessments.
\end{abstract}

Keywords: Fretting Fatigue, Fretting Wear, Crack Propagation, XFEM.

\section{Introduction}

The small relative movement which occurs between the contact surfaces of mechanical assemblies subjected to vibration can give rise to two different mechanical problems, fretting fatigue and fretting wear $[1,2,3]$. Fretting fatigue presents a small relative slip between the contact faces sufficient for one region of the contact zone to be stuck and the other part to slide (partial slip regime). In this type of fretting the wear effects are small and the initiation and further development of cracks is the dominant phenomenon. On the other hand, in case the amount of slip increases so that all corresponding points within the contact surfaces slide one with respect to the other, a gross slip regime takes place. In such a regime the crack initiation problem is limited due the high level of material removal caused by the wear in the contact region. Here fretting wear is the dominant mechanical problem $[4,5]$.

* Corresponding author 
This research work proposes a new total life approach for fretting fatigue. To compute the crack initiation life, fretting wear effects are taken into account. Further, a combination of the multiaxial fatigue damage parameter by SmithWhatson-Topper $(S W T)$, a linear damage accumulation law (Miner's law), and the theory of critical distance ( $T C D$, using point method) is used to predict the crack initiation life. In parallel, the effect of the fretting wear is considered using Archard's law [6, 7]. For a better understanding of this method, the reader can see the authors previous works $[8,9]$. The eXtended Finite Element Method (XFEM) is used for predicting the crack propagation path and the crack propagation lifetime. A new method is introduced to predict crack path under non-proportional loading conditions which is based on calculating the critical plane, based on the $S W T$ damage parameter, at and near the crack tip. Experimental results obtained by Reza et al. [10] are used to validate the numerical methodology proposed.

\section{Life assessment}

\subsection{Multiaxial fatigue life assessment}

Mechanical components under fretting conditions experience a multiaxial stress field under the contact surface. In this work, two different multiaxial fatigue models based on the critical plane approach are considered.

\subsubsection{Smith, Watson and Topper parameter (SWT)}

This critical plane criterion is better suited for materials and loading conditions where cracks propagate perpendicular to the direction of maximum principal stress and strain (Mode I cracks) $[11,12]$. The $S W T$ parameter can be defined as:

$$
S W T=\sigma_{n, \max } \epsilon_{n, a}
$$

where $\sigma_{n, \max }$ and $\epsilon_{n, a}$ are the maximum normal stress and the normal strain amplitude on the material plane that maximizes their product. It also allows estimating the component life by reference to a fully reversed uniaxial test where stress (Basquin) and strain (Coffin Manson) life relations can be combined yielding:

$$
\sigma_{n, \max } \epsilon_{n, a}=\frac{\sigma_{f}^{\prime}}{E}\left(2 N_{f}\right)^{2 b}+\sigma_{f}^{\prime} \epsilon_{f}^{\prime}\left(2 N_{f}\right)^{b+c}
$$

where $\sigma_{f}^{\prime}$ and $\epsilon_{f}^{\prime}$ are the fatigue strength and ductility coefficients, respectively, while $b$ and $c$ are the fatigue strength and ductility exponents, respectively. 


\subsubsection{Fatemi-Socie parameter (FS)}

The $F S$ parameter is suitable for situations where material failure occurs in shear mode $[13,14]$. It can be expressed as:

$$
F S=\frac{\Delta \gamma_{\max }}{2}\left(1+k_{2} \frac{\sigma_{n, \max }}{\sigma_{y}}\right)
$$

where, $\Delta \gamma_{\max }$ is the maximum shear strain range, $\sigma_{y}$ is the yield strength and $k_{2}$ is a material constant.

To compute the number of cycles for crack initiation the following equation should be used:

$$
F S=\frac{\tau_{f}^{\prime}}{G}\left(2 N_{i}\right)^{b^{\prime}}+\gamma_{f}^{\prime}\left(2 N_{i}\right)^{c^{\prime}}
$$

where, $b^{\prime}$ and $c^{\prime}$ are respectively the fatigue strength exponent and the fatigue ductility exponent in torsion, $\gamma_{f}^{\prime}$ is shear fatigue ductility coefficient, $G$ is the shear modulus and $\tau_{f}$ is the fatigue strength coefficient in shear.

\subsection{Critical distance approach}

The Theory of Critical Distance (TCD) was first proposed in the 1930s by $[15,16]$. Over the years, several works have been carried out to test and improve the TCD $[17,18,19]$. Generally, the TCD is used in problems where there are stress gradients to minimize its effects. In summary, the method proposes the use of an effective stress, $\sigma_{\text {eff }}$, obtained in a volume of control around the stress raiser. Currently, this method can be simplified in three different approaches known as the area, line, and point methods. In the point method $\sigma_{\text {eff }}$ is defined as the tension obtained at a critical distance, $L$, from the stress raiser [20]. Due to its easy implementation, the point method was used in this work. For high cycle fatigue (HCF), the critical distance using the point method assumes the following form:

$$
L=\frac{1}{2 \pi}\left(\frac{\Delta K_{t h}}{\Delta \sigma_{-1}}\right)^{2}
$$

where, $\Delta K_{t h}$ is the threshold stress intensity factor range and $\Delta \sigma_{-1}$ is the uniaxial plain fatigue limit range, both obtained under fully reversed loading configurations. The values of the critical distances under fatigue and static loading are usually different. In this way, the critical distance, $L_{M}$, at mediumhigh cycle fatigue regime depends on the number of cycles to failure, $N_{f}$. In this work, as a simplifying procedure, one assumes that $L_{M}=L$ for any number of cycles. 


\section{Numerical methodology}

\subsection{Crack propagation direction}

The stresses and strains at the crack tip can be used to determine the crack propagation angle. Therefore, it is very important to use a numerical method that can estimate the stress field accurately. There are several methods available in the literature widely used to predict the crack trajectory such as: the Maximum Tangential Stress criterion (MTS) [21], the Maximum Energy Release Rate criterion $(M E R R)[22]$ and the zero $K_{I I}$ criterion $\left(K_{I I}=0\right)$ [23]. These methods are already implemented in the commercial FE software ABAQUS 6.14 .

Despite the popularity and easy implementation of this methods, their performance in applications such as fretting fatigue was unsatisfactory [10]. The fretting problem not only presents a non-linear behavior, i.e., it is load historydependent, but also has a non-proportional load. This explains why traditional methods are unable to predict the crack path in fretting problems. With this in mind, a new method is introduced to predict the crack propagation path under non-proportional loading conditions. It is based on the $S W T$ damage parameter, calculated at and near the crack tip.

\subsubsection{Methods based on the $S W T$ damage parameter}

Navarro et al. [24] proposed a methodology to predict the crack propagation in fretting fatigue problems without including one crack on the mesh. This methodology is based on multiaxial models of critical plane. Where the parameter is calculated for all points along a straight line of an arbitrary length starting from the contact trailing edge $(x=a)$ and forming an angle $\theta$ with a line perpendicular to the contact surface, as shown in Figure 1(a). The material plane that coincides with that defined by $\theta$ is considered for the criterion parameter evaluation instead of use that plane that produces the maximum parameter value. This is repeated for different values of $\theta$ and using the average value of each straight line is obtaining the polar contour depicted in Figure 1(b). This methodology assumes that those lines having the higher mean values of the parameter along a certain length are more likely to initiate cracks. The results obtained by Navarro et al. [24] shown that the prediction by using the $S W T$ parameter has been much closer to the experimental crack path than the FS parameter.

In this work, an adaptation of this method described above was carried out. For a better understanding, we call this approach $\left(S W T_{\text {mean }}\right)_{\max }$. The procedure is exactly the same with the difference that now a crack is included in the mesh using the XFEM method. Basically the $\left(S W T_{\text {mean }}\right)_{\max }$ defines that the crack will grow in the plane where the average of the $S W T$ parameter values is maximum.

Two other alternative methods to compute the crack path, also based on the $S W T$ parameter, are here proposed. The first, $S W T_{t i p}$, considers the stress/strain history at a single material point on the crack tip to obtain the 
a)

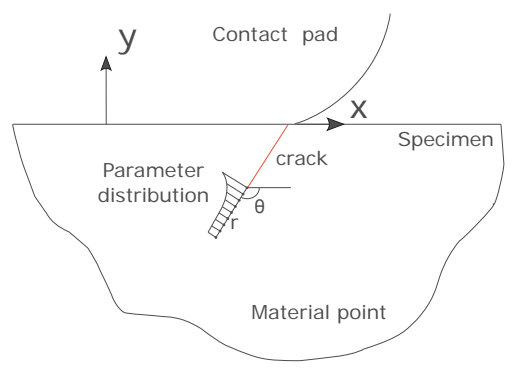

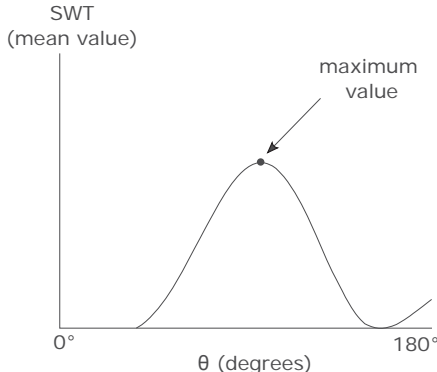

Figure 1: Illustration of the strategy used to $\left(S W T_{\text {mean }}\right)_{\max }$.

orientation of the incremental crack growth plane. Such procedure is then repeated at each step of the simulation until the crack reaches $2 \mathrm{~mm}$ size (size of the experimentally detected cracks to stop the tests). The second method, denominated $S W T_{L_{0}}$, computes the $S W T$ crack orientation plane from the stress/strain history of material point distant $L / 2$ from the crack tip, where $L$ is the critical distance given by Eq. (5).

\subsection{Wear modelling and damage accumulation}

\subsubsection{Wear model}

Among the most well-known wear models, especially in fretting fatigue applications, we can highlight for their wide use and easy applicability the local formulations of Archard's equation [7, 25] or the dissipated friction energy $[26,27]$. Archard's equation for sliding wear can be expressed as [6]:

$$
\frac{V}{S}=\frac{K}{H} P
$$

where $P, S$, and $V$ are the normal contact load, total relative slip, and volume of material removed, respectively. $K$ is the dimensionless wear coefficient and $H$ is the material hardness. In Eq. (6), the ratio $K / H$ can be replaced by the specific wear coefficient, $k$. In terms of a local expression, the wear can for an infinitesimal area be written described as:

$$
d h=k_{w} p(x) d s
$$

where $p$ is the contact pressure and $k_{w}$ the local wear coefficient and $d h$ is the material removal depth for a given incremental relative slip $d s$.

Eq. (7) can be used to compute wear locally. However, in the context of an FE code, it is necessary to make some changes. From a practical point of view, the simulation of all the desired wear cycles is not feasible. In this case, a strategy commonly adopted is to compute the wear during a fretting cycle and then multiply it by the jumping factor $\Delta N$ assuming that the wear is 
nearly constant for $\Delta N$ wear cycles. This way, each contact surface node will be updated after the application of the $i_{t h}$ wear block $\Delta N$ as follows:

$$
\Delta h_{i, j}=\sum_{k=1}^{n_{\text {inc }}} k_{w} p\left(x_{j}, t_{k}\right) \Delta s\left(x_{j}, t_{k}\right) \Delta N
$$

where $\Delta h_{i, j}$ is the wear depth increment of the node $j$ located at the contact surface with position $x_{j}, k_{w}$ is the local wear coefficient and $n_{i n c}$ is the total number of load increments over a fretting cycle. The contact variables $p\left(x_{j}, t_{k}\right)$ and $\Delta s\left(x_{j}, t_{k}\right)$ are respectively, the pressure distribution and the contact relative slip increment for the node $j$ at the time increment $t_{k}$. The total required number of wear cycles, $N_{t}$, can be split in $n_{w}$ wear blocks, where each block corresponds to $\Delta N$ wear cycles, i.e. $n_{w}=N_{t} / \Delta N$. Thus, the total wear depth at $N_{t}$ cycles for the node $j$ is given by:

$$
h_{j}=\sum_{i=1}^{n_{w}} \Delta h_{i, j}
$$

\subsubsection{Damage accumulation method}

With the evolution of wear, the stresses and strains change in each simulated fretting cycle. Thus, it is necessary to calculate the damage in each wear step. Miner's linear cumulative damage rule $[28,29]$ was used in this work to predict material failure. For a material sub-surface point $\mathbf{x}$, the total cumulative damage associated with the $n^{t h}$ wear step is given by:

$$
D_{f, n}(\mathbf{x})=\sum_{i=1}^{n} \frac{\Delta N}{N_{f, i}(\mathbf{x})}
$$

where $N_{f, i}$ is the fatigue life expected for a given stress state, i.e. a multiaxial fatigue model is used after determining the stress state $\sigma(\mathbf{x}, t)$ for given material point $\mathbf{x}$ and time instant $t$ over the $i^{\text {th }}$ fretting cycle to predict the fatigue life $N_{f, i}(\mathbf{x})$. The centroid of the elements was defined as the position to compute the damage defined by Eq.(10). Due to the evolution of wear, the contact surface is constantly changing, thus the position of the nodes, and consequently the centroid of the elements are changed. Therefore, the following numerical scheme was adopted: as can be seen on Figure 2, after each $i^{\text {th }}$ fretting cycle simulation, the damage value on the $(i-1)^{t h}$ fretting cycle was interpolated from the $(i-1)^{t h}$ element centroids position to the new $i^{t h}$ element centroids location. Given this, the actual damage field distribution at the $i^{\text {th }}$ damage increment can be expressed as:

$$
D_{f, i}=D_{f, i-1}^{*}+\Delta D_{f, i}
$$


where $D_{f, i-1}^{*}$ is the damage field from the previous fretting cycle simulation $(i-1)^{t h}$ interpolated to the position of the element centroid points at the $i^{t h}$ fretting cycle. This strategy for the damage accumulation is the same used in $[8,9]$, however, this research work proposes a different technique for the contact surface update. Instead of using the remesh technique like in previous works, the moving node technique was used, where the position of the nodes on the contact surface is changed in each step using the same mesh in all simulations. For more details concerning their implementation see Appendix A.
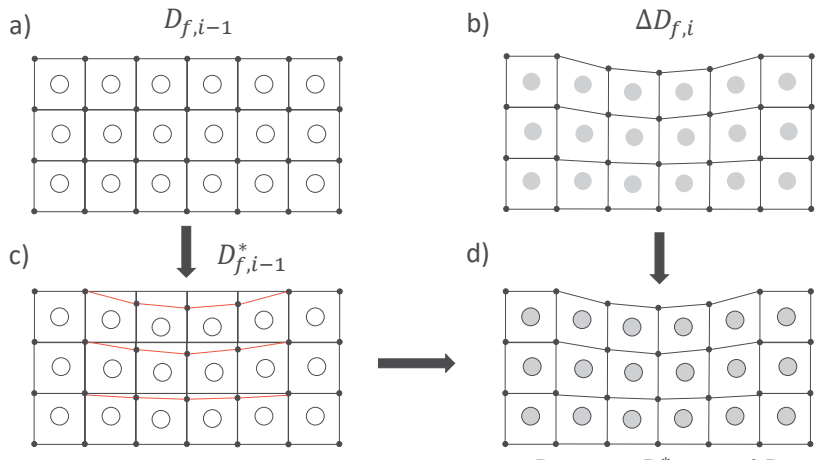

d)

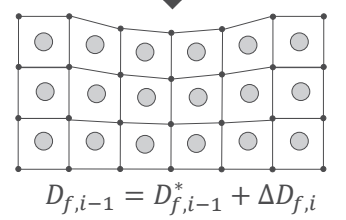

Figure 2: Illustration of the strategy used in order to compute the damage considering wear process: (a) accumulated damage at the centroid of the elements at the $(i-1)^{t h}$ simulated fretting cycle, (b) incremental damage at the centroid of the elements at the $i^{\text {th }}$ simulated fretting cycle, (c) accumulating cycle extrapolated to the position of the element centroids at the $i^{t h}$ simulated fretting cycle and (d) accumulation of the total damage at the $i^{t h}$ simulated fretting cycle.

\section{Experimental data}

In this work, the experimental data obtained by Talemi et al. [10] were used to validate the proposed method in this research. The material used was aluminum 2024-T3, a tempered aerospace aluminum with good fatigue properties. All the test specimens were produced from a single sheet of aluminum 2024-T3. The mechanical properties from the specification sheet are reported in Table 1. Table 2 shows the loading conditions in each fretting fatigue test and respective life observed, where $\mathrm{B}$ represents the bulk fatigue load, $\mathrm{R}$ is the pad radius, $\mathrm{P}$ is the normal force, $\mathrm{Q}_{\max }$ is the tangential load and $N_{f}$ is the experimental total life to the complete failure of the specimes.

Two multiaxial fatigue models were used for life assessment, SWT (SmithWatson-Topper) and FS (Fatemi-Socie). To calibrate these fatigue models data provided by Newman et al. were used [30]. The S-N curve was obtained considering uniaxial tests for different load ratios as shown in Figure 3(a). The parameters $S W T$ and $F S$ were calibrated for total life, $N_{f}$, and crack nucleation life, $N_{i}$, see Figures 4 and 5 . To calibrate the parameters for total life, 
Table 1: Mechanical properties of Al2024-T3 [10].

\begin{tabular}{lcc}
\hline \multicolumn{3}{c}{ Monotonic properties } \\
\hline Young's modulus & $E$ & $72.1 \mathrm{GPa}$ \\
Poisson's modulus & $v$ & 0.33 \\
Yield strength & $\sigma_{y}$ & $383 \mathrm{MPa}$ \\
Ultimate tensile strength & $\sigma_{u t}$ & $506 \mathrm{MPa}$ \\
Fracture toughness & $K_{c}$ & $2083 \mathrm{MPa} \sqrt{m m}$ \\
Coefficient of friction & $\mu$ & 0.65 \\
\hline \multicolumn{3}{c}{ Cyclic properties } \\
\hline Threshold stress intensity factor & $\Delta K_{t h}$ & $100 \mathrm{MPa} \sqrt{m m}$ \\
Uniaxial plain fatigue limit & $\Delta \sigma_{-1}$ & $263 \mathrm{MPa}$ \\
Critical distance & $L$ & $23 \mu \mathrm{m}$ \\
\hline
\end{tabular}

Table 2: Test conditions of fretting fatigue experiments [10].

$\begin{array}{lccccc}\text { Test no. } & \mathbf{B}(\mathbf{M P a}) & \mathbf{R}(\mathbf{m m}) & \mathbf{P}(\mathbf{N}) & \mathbf{Q}_{\max }(\mathbf{N}) & N_{f}(-) \\ \text { FF1 } & 100 & 50 & 543 & 155.17 & 1,407,257 \\ \text { FF2 } & 115 & 50 & 543 & 186.25 & 1,105,245 \\ \text { FF3 } & 135 & 50 & 543 & 223.70 & 358,082 \\ \text { FF4 } & 135 & 50 & 543 & 195.55 & 419,919 \\ \text { FF5 } & 160 & 50 & 543 & 193.70 & 245,690 \\ \text { FF6 } & 190 & 50 & 543 & 330.15 & 141,890 \\ \text { FF7 } & 205 & 50 & 543 & 322.10 & 114,645 \\ \text { FF8 } & 220 & 50 & 543 & 267.15 & 99,607 \\ \text { FF9 } & 220 & 50 & 543 & 317.85 & 86,647\end{array}$

we have just used the same data obtained in the literature, as they are for total fracture. However, for crack nucleation life, it is necessary to subtract the crack propagation life from the data, as in Figure 3(b). Therefore, considering an initial crack of $100 \mu \mathrm{m}$, the propagation life $N_{p}$ was estimated for all data using Paris' law. In this way, it was enough to subtract the propagation from the total life. Then calibrate the multiaxial parameter for crack nucleation.

To compute the wear using Archard's equation, it is crucial to determine the local wear coefficient $k$. Ashwin et al. [31] performed wear tests on 2024-T351 aluminum alloy specimens. The results indicate that the wear rate obtained was in the order of $10^{-7} \mathrm{~g} / \mathrm{Nm}$ for the tested parameter conditions. Conservatively, in this work, the lowest value for the wear coefficient was used. According to Eq. (6), it is enough to divide the wear rate by the density of the material $(7,28$ $\left.\mathrm{g} / \mathrm{cm}^{3}\right)$ to obtain the local wear coefficient. Thus, the local wear coefficient was defined as $k=5.81 \times 10^{-8} \mathrm{MPa}^{-1}$. 
a)

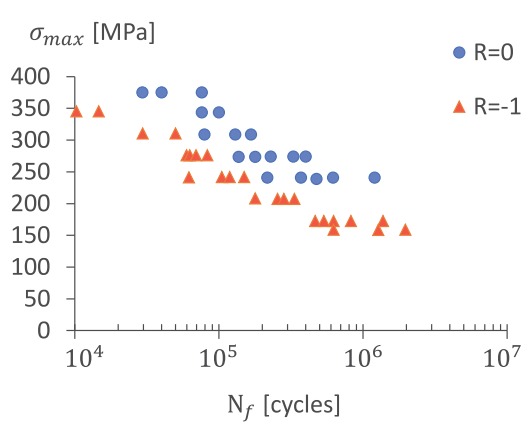

b)

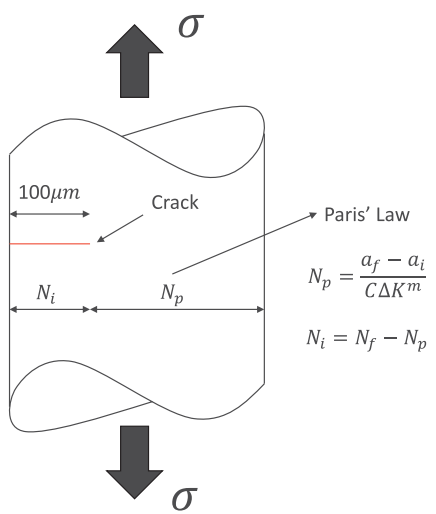

Figure 3: Uniaxial fatigue data for the Al 2024-T351 [30] (a), process of crack nucleation life estimation (b).
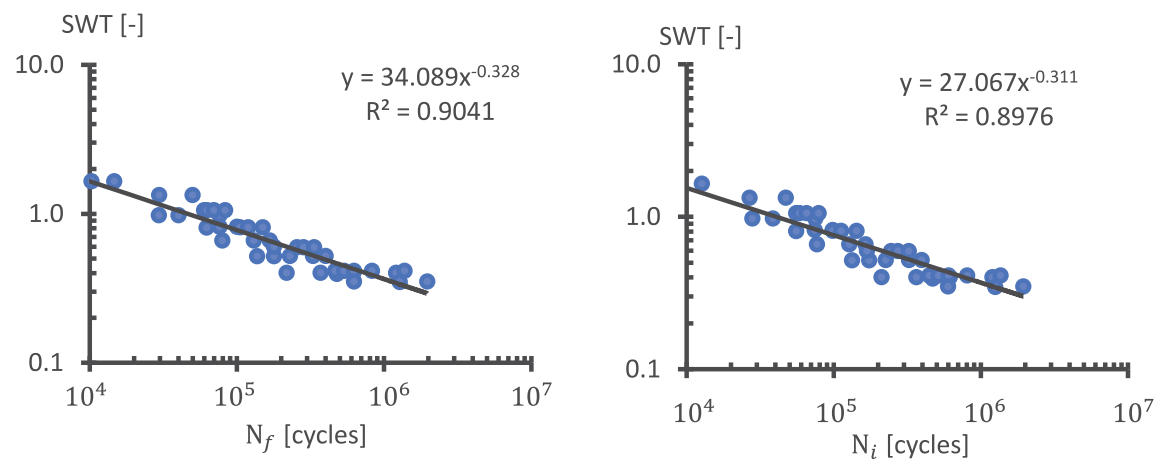

Figure 4: Uniaxial fatigue data for the Al 2024-T3 expressed in terms of the SWT parameter.
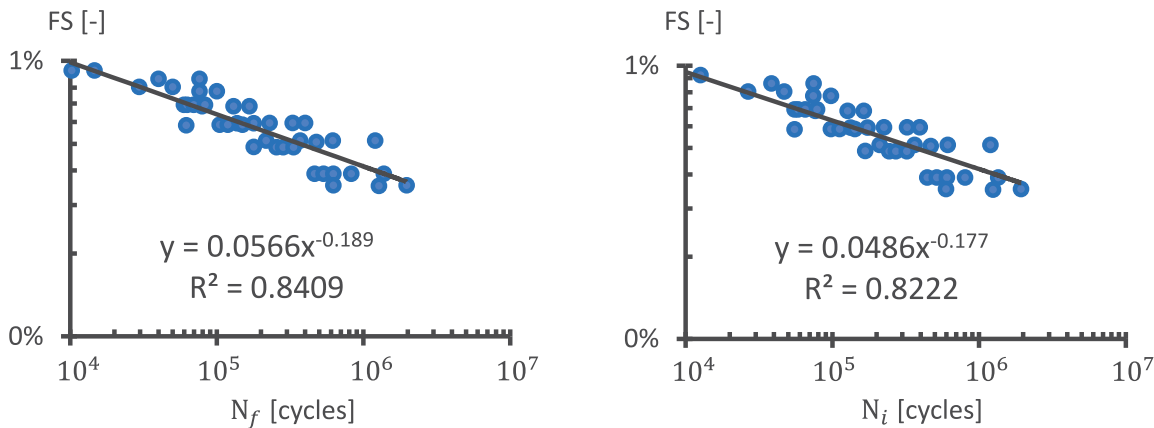

Figure 5: Uniaxial fatigue data for the Al 2024-T3 expressed in terms of the FS parameter. 


\section{Results and discussions}

\subsection{Validation of the XFEM method for crack propagation}

The first tests done with the XFEM method were performed using a cracked plate under tension as illustrated in Figure $6(\mathrm{a})$. Where, $\mathrm{b}=50 \mathrm{~mm}, \mathrm{~h}=50 \mathrm{~mm}$, $\mathrm{t}=10 \mathrm{~mm}$ and $\mathrm{a}=5 \mathrm{~mm}\left(\mathrm{a}_{i} / \mathrm{b}=0.1\right.$ and $\left.\mathrm{a}_{f} / \mathrm{b}=0.28\right)$. The crack was modeled using the software ABAQUS 6.14. Figure 6(b) shows how this crack was modeled and the mesh size used. The mesh size was $0.7 \mathrm{~mm}$ and the crack face was modeled through the elements. Note that the crack tip is located at the edge of the last element.

a)

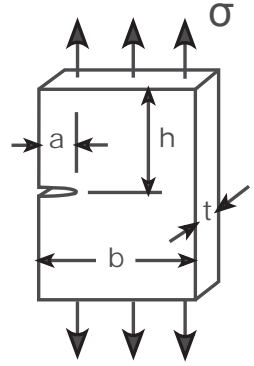

b)

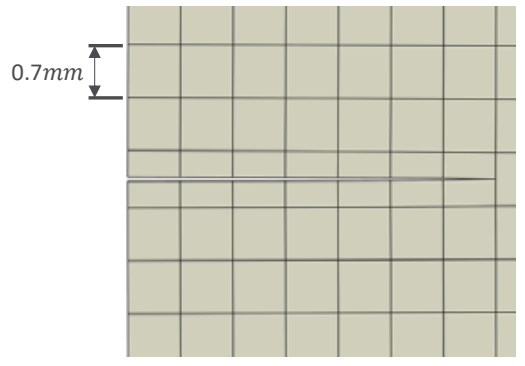

Figure 6: Cracked plate under tension (a) and crack modeling with XFEM(b).

a)

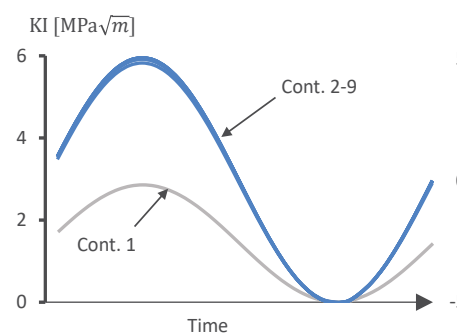

$\mathrm{KII}[\mathrm{MPa} \sqrt{m}]$

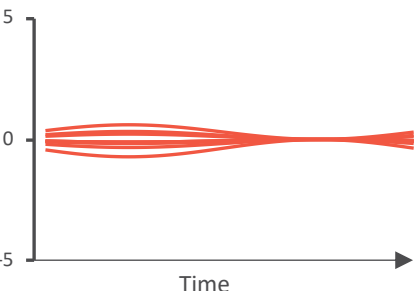

Figure 7: Time variation of $K_{I}(\mathrm{a})$ and $K_{I I}(\mathrm{~b})$.

Figures $7(\mathrm{a})$ and (b) show the variation of the stress intensity factor $K_{I}$ and $K_{I I}$ respectively for an initial crack of $2 \mathrm{~mm}$ in a loading cycle with $\mathrm{R}=0$. For two-dimensional problems, the XFEM method was implemented on Abaqus to crack growing in monotonic loading. Therefore, the XFEM formulation related to the enrichment of the nodes at the crack tip is neglected. Thus, the $K_{I}$ and $K_{I I}$ values obtained using the first contour (crack tip position) are underestimated, as can be seen clearly in Figure 7(a). 
a)

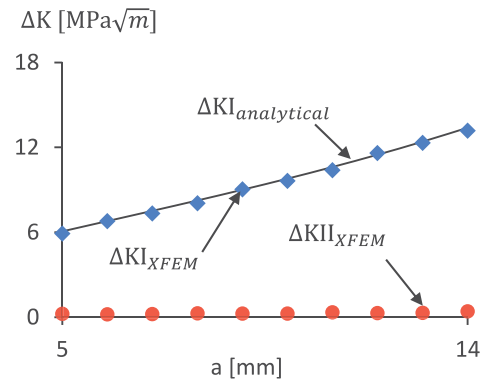

b)

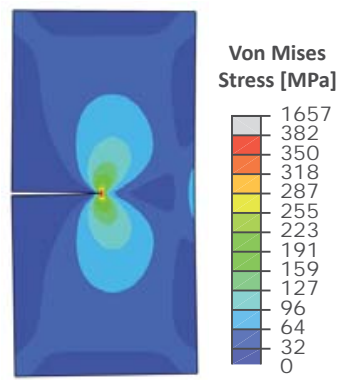

Figure 8: Analytical vs numerical stress intensity factor (a) and numerical results of the stress field at the crack tip (b).

With these in mind, the analysis was carried out using only the contours up 2 to 9 . Figure $8(\mathrm{a})$ shows the results of $\triangle K_{I, X F E M}$ and $\triangle K_{I I, X F E M}$ obtained numerically against analytical values. The $M T S$ method was used to estimate the crack propagation angle. The final result of the crack trajectory and the stress field around the crack tip can be seen in Figure 8(b).

As previously mentioned, when the crack is modeled in two-dimensional problems with XFEM in Abaqus the crack tip enrichment is neglected. So, the best strategy would be to ignore the $K_{I}$ and $K_{I I}$ values obtained on the first contour. The numerical values for $K_{I}$ and $K_{I I}$ obtained this way showed to be in good agreement with the analytical solution, the divergence is insignificant. As the loading condition used for this validation is proportional the MTS method resulted in a good crack trajectory prediction.

\subsection{Comparison between different crack path prediction methods}

The well-known methods for crack path prediction are Maximum Tangential Stress $(M T S), K_{I I}=0$, and Maximum Energy Release Rate (MERR) among others. These three methods are already implemented as a standard tool in Abaqus. Despite being well known and used, these methods do not take into account the non-linear behavior and the effects of non-proportional loading. Therefore, a new method is introduced to predict the crack propagation path under non-proportional loading conditions which is based on calculating the critical plane, based on the $S W T$ damage parameter, at and near the crack tip. Three different values of $S W T$ damage parameters are calculated, i.e. $\left(S W T_{\text {mean }}\right)_{\max }, S W T_{\text {tip }}, S W T_{L_{0}}$.

Figure 9 depicts the FE model, loading and geometric configurations. In this investigation were used the following loads $\mathrm{Q}=155.165 \mathrm{~N}, \mathrm{~B}=100 \mathrm{MPa}$, and $\mathrm{P}$ $=543 \mathrm{~N}$. A pad of radius $\mathrm{R}=50 \mathrm{~mm}$ and thickness of $10 \mathrm{~mm}$ was used. A coarser mesh is used far from the contact region, whereas, a refined one is considered near the contacting surfaces. In the refined region, a structured mesh with linear quadrilateral elements are used with an approximate size of $11.5 \mu \mathrm{m}$. Outside 
the refinement zone, the mesh is not structured but is formed by the same kinds of elements. For all simulations plane strain elements are considered in the analyses. Multi-point constraints are enforced on the upper surface of the pad so that rotation is prevented. Regarding the contact conditions, the Lagrange multiplier approach was used to define the frictional contact constraints, and the contact nodes located at the specimen were defined as the master ones while the slave nodes were set on the pad.

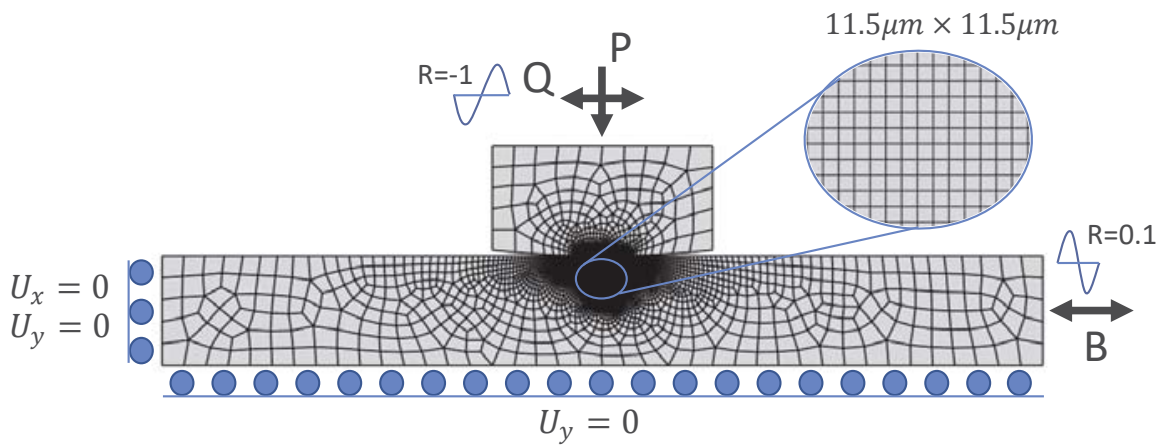

Figure 9: FE model, loading and geometric configurations.

a)

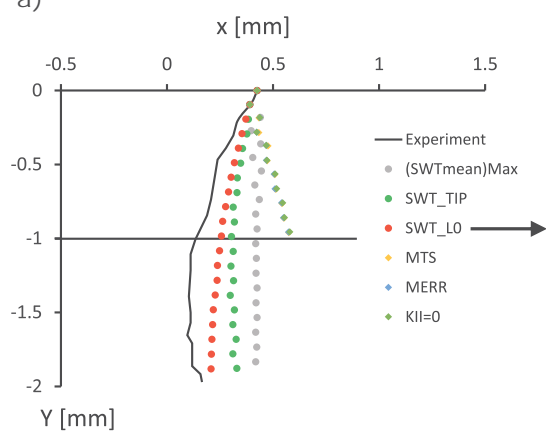

b)

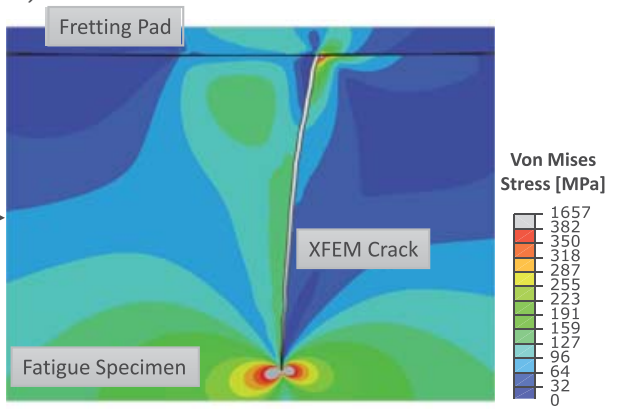

Figure 10: Comparing the estimated crack propagation path using different criteria and the experimental observation.

Figure 10 compares the estimated crack propagation path using different criteria and experimental observation. As expected, the traditional methods $\left(M T S, M E R R\right.$, and $\left.K_{I I}=0\right)$ that do not take into account the effects of non-proportional loading underperformed, where the crack propagates in the opposite direction to the direction of propagation observed experimentally. The three methods based on the critical plane multiaxial model had better results, where the method that applies the $S W T$ parameter at a critical distance, $L$, had a better response. The use of stress in $L$ for the calculation of the critical 
plane avoids the effects of the stress gradient at the crack tip, this may explain the crack path estimated smoother than with the other methods.

\subsubsection{Convergence analysis}

The previous analyses have shown that the $S W T_{L_{0}}$ method performed better to predict the crack path. Therefore, three tests were carried out with different mesh sizes to verify the influence of the mesh on the crack path and later on the $K_{I}$ and $K_{I I}$ values.

Figure 11(a) shows that the mesh size does not interfere with the expected crack path. This is because the proposed method is based on the stress and strain field close to the crack. Therefore, as long as the mesh is refined enough to obtain a good estimate of the stress/strain field, the size of the elements will no longer interfere with the estimate of the crack propagation angle.

However, Figure 11(b) shows that when is used mesh size of $46 \mu \mathrm{m}$ there is a small variation for $\Delta K_{e q} / K_{c}$ in the initial crack growth phase, in which $\Delta K_{e q}=$ $\sqrt{\Delta K_{I}^{2}+\Delta K_{I I}^{2}}$ and $K_{c}$ is the fracture toughness. As the XFEM method allows complete separation of the element at the crack tip. The ratio between mesh and crack increment size, Mesh/da, should be as small as possible. In this study $d a=100 \mu \mathrm{m}$ was used, so a mesh with $46 \mu \mathrm{m}$ elements size represents almost $50 \%$ of $d a$. This makes the crack after the simulation greater than expected, causing a significant error in the life estimate, as shown in Figure 12. Note that for meshes with elements smaller than $23 \mu \mathrm{m}$ the results start to converge.

a)

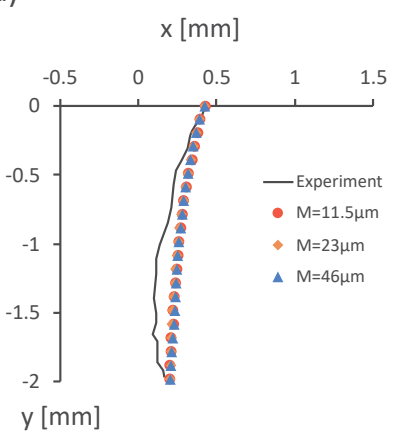

b)

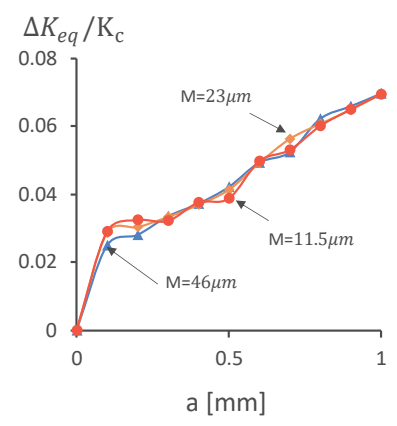

Figure 11: Convergence analysis using different mesh size: crack path (a) and Stress Intensity Factor variation (b).

\subsection{Application of XFEM and $S W T_{L_{0}}$ method for crack propagation life and path estimation}

The previous results showed that the XFEM method can be used to calculate the SIFs (Stress Intensity Factors) with good accuracy. It was also observed that the $S W T_{L_{0}}$ method has a better performance for crack trajectory prediction than the usual methods that do not consider non-proportional loading effects. 


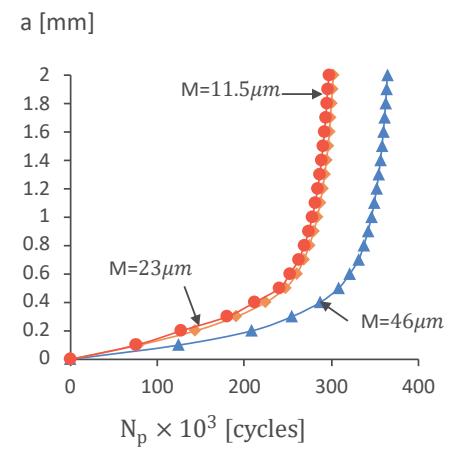

Figure 12: Life estimation using different mesh size.

With this in mind, these two techniques were used to estimate the life and crack trajectory of the fretting fatigue tests performed by Talemi et al. [10].

\subsubsection{Crack path and propagation life analyses}

The location of the initial crack was calculated based on the maximum location of dissipated energy at the contact interface during one full cyclic loading condition. The crack initiation angle was defined as based on experimental observation. The concept of cumulative dissipated energy, $E_{d}$, was introduced by Monhrbacher et al. [32]. The total dissipated energy after one cycle can be written as in Eq. (12), where $\tau_{i}$ is the frictional shear stress distribution and $\delta_{i}$ is the local slip amplitude.

$$
E_{d}=\sum_{i=1}^{n} \tau_{i} \times \delta_{i}
$$

Figure 13(a) shows the trajectories obtained using the methods proposed in this work. It is noted that, even with the increase in the magnitude of the loads and different initial crack location, the trajectory of the crack is practically the same for all cases. However, despite a similar trajectory, the crack propagation life can be quite different, as shown in Figure 13(b).

The large variation in the estimated life is because tests with load configurations of greater magnitudes have a higher initial $\Delta K_{e q} / \Delta K_{I c}$ ratio, as shown in Figure 14(a). This implies that loads with this higher initial ratio will reach faster the crack propagation stage III, in other words, will have shorter lives.

Figure 14(b) shows the percentage of crack propagation life estimated for all tests performed in this work. As can be seen, subtracting the crack propagation life estimated by the total experimental life, we have an average estimation of $86 \%$ of the total life composed by the crack initiation life.

\subsubsection{Multiaxial fatigue life assessment}

In this section, two different approaches were used to estimate life. The first method, better known and easier to implement, is illustrated in Figure 
a)

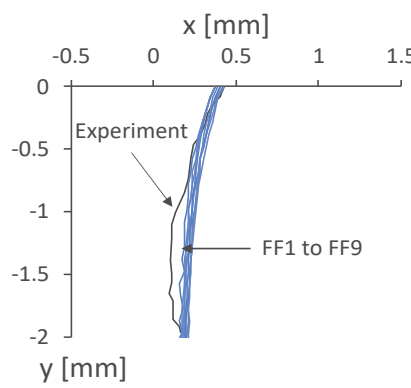

b)

$\mathrm{a}[\mathrm{mm}]$

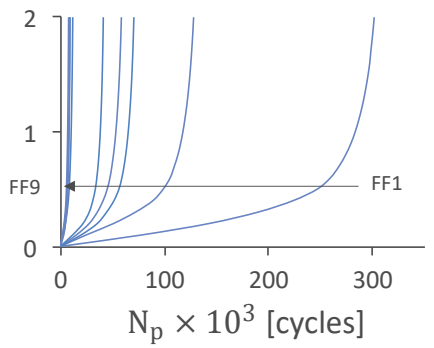

Figure 13: Crack propagation trajectory (a) and Variation of the crack length versus crack propagation life time (b) for FF1-FF9.

a)

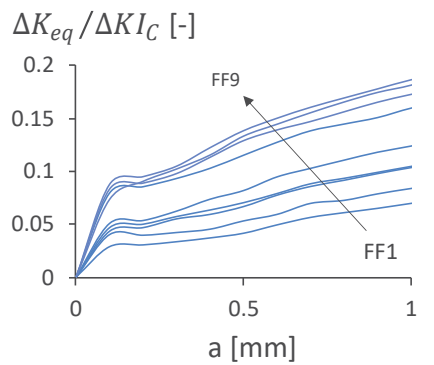

b)

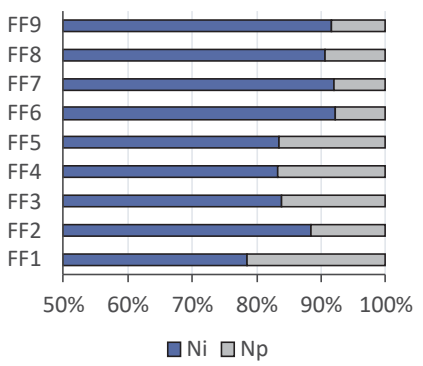

Figure 14: Variation of normalized equivalent SIFs versus the crack length for FF1-FF9 (a) and Estimated percentage of fretting fatigue crack initiation and propagation lifetime (b).

15. In this method, the stress/strain history in a single material point is used to estimate life. The abscissa of such a point is defined at the edge of the contact zone, $a$, while the ordinate is located at a critical distance from the contact surface, L. L, is determined by Eq. (5). Generally, stresses/strains at a distance $L$ from the contact surface are used to mitigate the effects of the high-stress gradient generated by the contact surface. In this first approach, the parameters $S W T$ and $F S$, calibrated for total failure, are used to estimate life.

Figure 16 illustrates the second approach used. In this method, more complex than the first, life is divided between crack nucleation, $N_{i}$, and crack propagation life, $N_{p}$. In which, the sum of the two represents the total life. For the calculation of $N_{i}$, an approach similar to the first method is used. The stress/strain history of a given point is also used to estimate life. However, in this case, the multiaxial parameters used are calibrated for crack nucleation and not to total failure. In addition, the coordinates of this point are also different. Horizontally it is defined as the one where the dissipated energy is maximum, Eq. (12). Figure 17 shows the dissipated energy profile in all the tests analyzed 


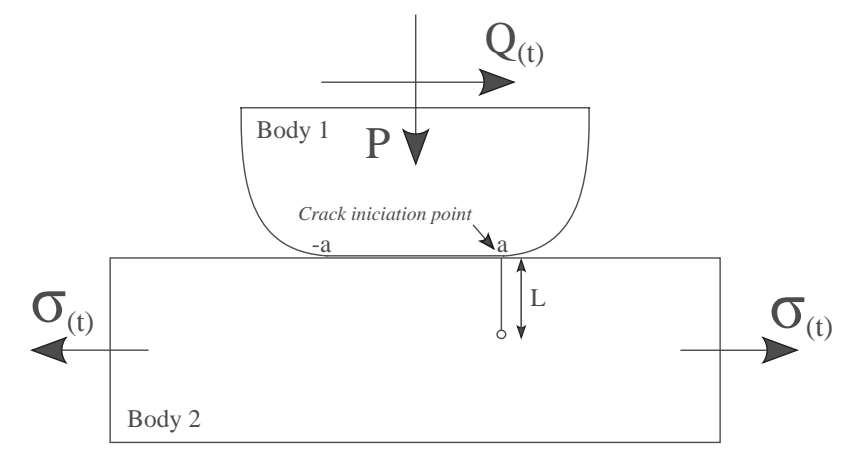

Figure 15: Procedure for estimating fatigue life when crack poagation life and wear are neglected.

and a table with the location where the $E_{d}$ is maximum. Vertically, it is defined as the critical distance from the contact surface, $L$. The propagation life, $N_{p}$, is obtained through the solutions proposed by means of Paris law and the techniques developed in Section 5.3.1. Thus, the total life is $N_{f}=N_{i}+N_{p}$.

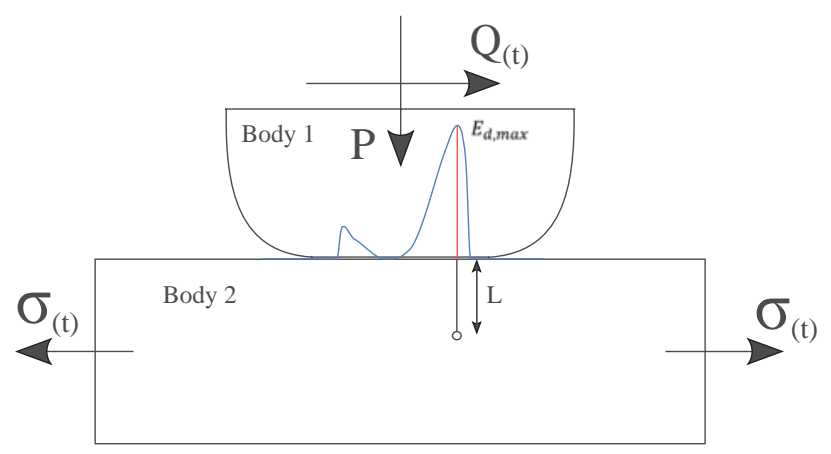

Figure 16: Procedure for estimating fatigue life with crack propagation without wear.

Figure 18 presents the results for the two approaches. In which, $N_{f, S W T}$ and $N_{f, F S}$ are the results for the first approach (without crack propagation) using the parameters $S W T$ and $F S$ respectively. And the results of the second approach are $N_{i, S W T}+N_{p, X F E M}$ and $N_{i, F S}+N_{p, X F E M}$ for the parameters $S W T$ and $F S$ respectively. In this figure, the predicted life is plotted against the experimental life and delimited by a scatter band equal to 2 . The results in Figure 18 show that for long lives $F S$ parameter has a greater error since most of the results are above the solid line, while $S W T$ presents better and more conservative performance. On the another hand, for short lives both $S W T$ and 


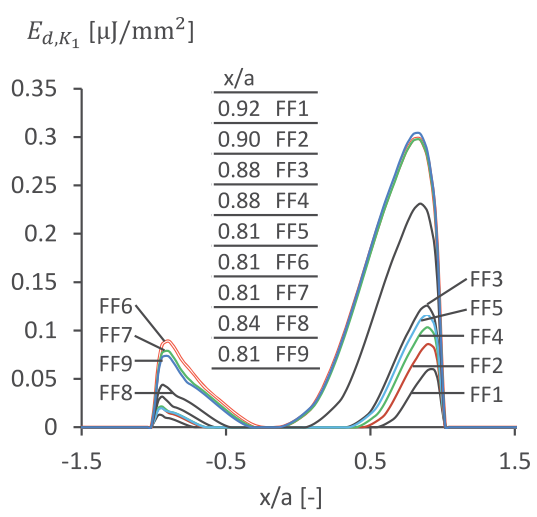

Figure 17: The energy dissipated along the surface contact for FF1-FF9.

$F S$ are conservative. Although $N_{f, S W T}$ fall out the scatter band 2, the error is close to $50 \%$. However, using the method $N_{i, S W T}+N_{p, X F E M}$ this problem is solved and all data fall into the scatter band 2 .

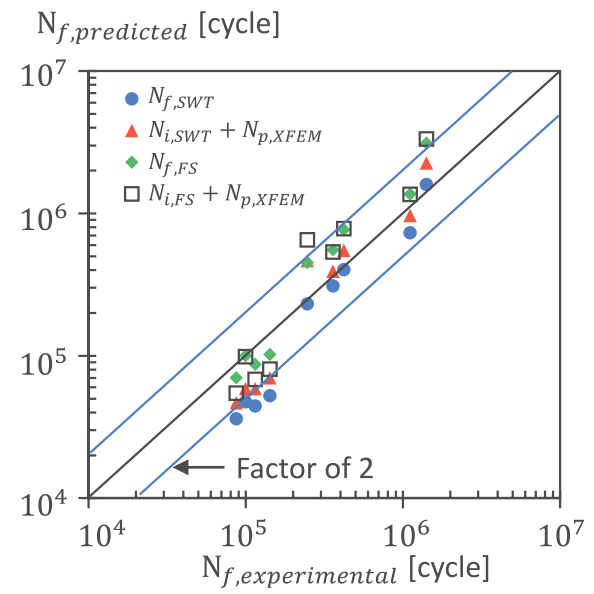

Figure 18: Estimated and observed fretting fatigue lives without and with crack propagation.

\subsection{Effects of fretting wear process on fatigue crack propagation}

In this section, results will be presented including the effect of surface wear on the contact region during the crack nucleation phase. Wear effect can be computed using the local formulation of Archad's equation or the dissipated friction energy. In this work was adopted Archad's equation, which can be computed using Eq. (8). As shown in Section 5.3.2, the parameter $S W T$ provides 
more conservative results than $F S$ for the material in question. Therefore, in all tests including the wear effect, only the multiaxial parameter $S W T$ was applied.

Figure 19(a) shows the difference between the contact surfaces before and after the effect of wear. There is a clear separation between the stick zone and slip zones. This is because the region where there is no relative slip the wear is not computed. The pressure distribution profile, depicted in Figure 19(b), has a small increase in the central region of the contact. However, while in the slip zones the pressure values are almost zero, peaks in the transitions between stick and slip zones are observed.

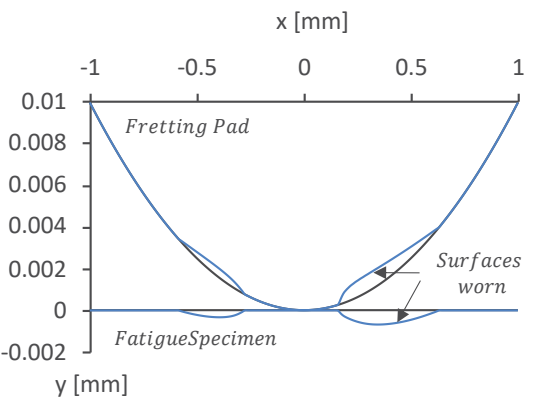

$p(x)[\mathrm{MPa}]$

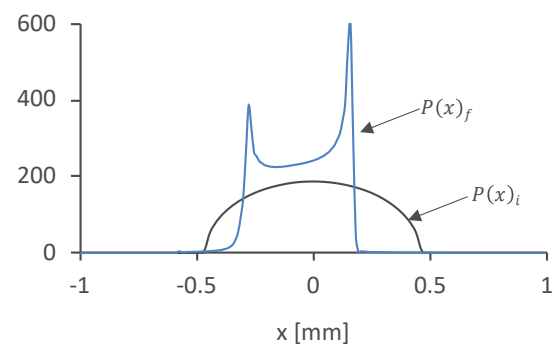

Figure 19: Comparison between surfaces (a) and normal pressure distribution (b) after wear process to FF4 test.

a)

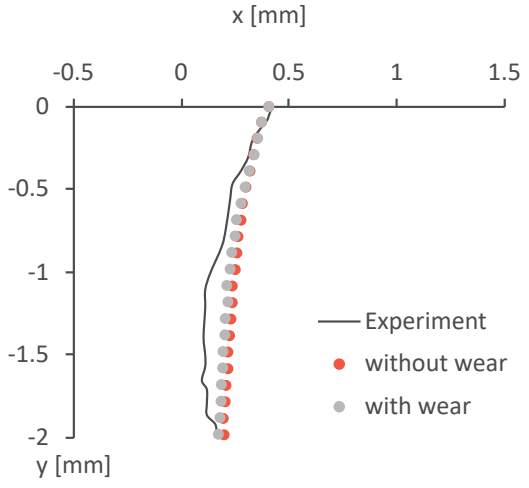

b)

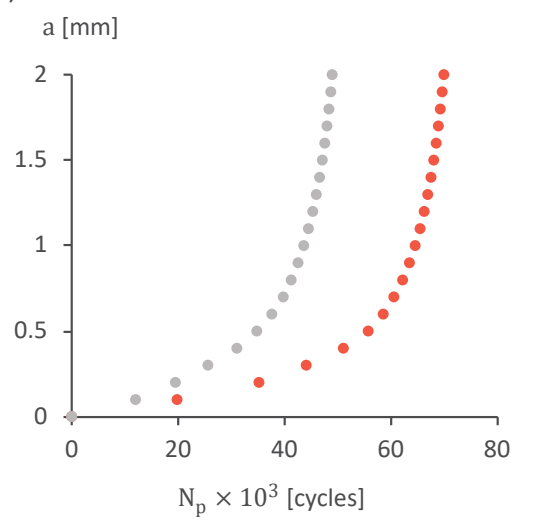

Figure 20: Comparison between crack path (a) and crack propagation life (b) after wear process to FF4 test.

Figure 20 shows the crack propagation results using the methods described in the previous sections with and without the wear effect. In Figure 20(a) it 
is observed that the inclusion of wear practically does not change the crack path. On the other hand, the crack propagation life with the worn surface is approximately $30 \%$ less than when the wear effect is neglected. The results presented in this section are only for the FF4 test. The same behavior was observed for all tests and can be seen at Appendix B.

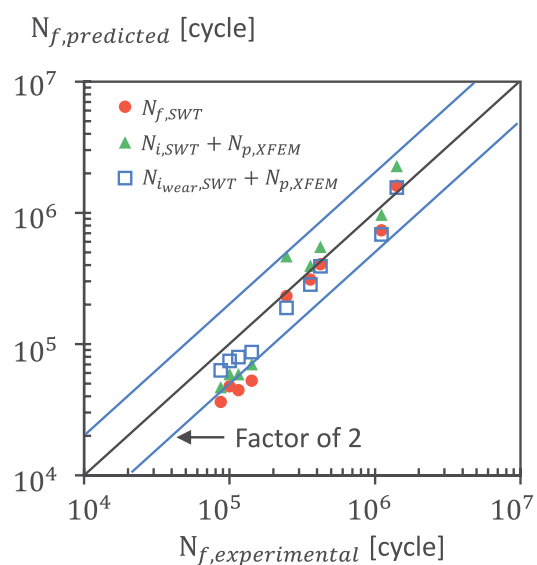

Figure 21: Estimated and observed fretting fatigue lives without and with crack propagation including wear effect.

As stated earlier, the $S W T$ parameter has been more conservative in general than the FS. Therefore, the analysis including wear was performed only with the $S W T$. The results of life assessment can be seen in Figure 21. It is noted that when the model is applied conventionally, i.e., without including wear effect and crack propagation, the life predictions are close to the experimental results for longer lives. While, in tests with shorter lives, the results fall out the scatter band 2 .

Using the methodology where life is separated into nucleation and crack propagation life, there is a small improvement in data that fell out the scatter band 2. The other tests continue within the desired region, but with less conservative predictions and a dispersion a little higher in these cases. Taking wear into account in the crack initiation phase could correct the dispersion previously found for tests with longer life and the life estimation remained conservative. However, the life predictions were very close to those obtained without wear effect and crack propagation life. The inclusion of the wear effect brought a clear benefit for tests with a shorter life, which not only falls into the scatter band 2 , but the error in the prediction became smaller than in the other two approaches.

Over time, surface wear changes the contact geometry by increasing the stress concentration. Apparently, with higher stresses, the life estimate should be lower. However, the material loss on the contact surface, in theory, can remove micro-cracks causing retardation in the nucleation of new cracks. Con- 
sequently, this behavior generates an extension of life. In numerical terms, the movement of the nodes on the contact surface represents this loss of material. This movement reflects the damage accumulation in each element since the incremental damage from the previous step is interpolated to the new position with the worn surface. This process delays the evolution of the damage providing a longer life estimate. This behavior explains why there was an improvement in the estimated data, mainly in those tests with shorter lives.

Table 3: Result of life assessment with and without take wear into account, checking the influence of wear in $N_{i}$ and $N_{p}$.

\begin{tabular}{c|cc|cc|ccc} 
& \multicolumn{2}{|c|}{ With wear } & \multicolumn{2}{|c|}{ Without wear } & \multicolumn{2}{c}{$\left(\mathbf{N}_{\mathbf{i}, \mathbf{p}_{\text {wear }}}-\mathbf{N}_{\mathbf{i}, \mathbf{p}}\right) / \mathbf{N}_{\mathbf{i}, \mathbf{p}}$} \\
\hline Test & $\mathbf{N}_{\mathbf{i}}$ & $\mathbf{N}_{\mathbf{p}}$ & $\mathbf{N}_{\mathbf{i}}$ & $\mathbf{N}_{\mathbf{p}}$ & $\boldsymbol{\Delta} \mathbf{N}_{\mathbf{i}}$ & $\boldsymbol{\Delta} \mathbf{N}_{\mathbf{p}}$ & $\boldsymbol{\Delta} \mathbf{N}_{\mathbf{f}}$ \\
\hline FF1 & $1,390,000$ & 168,200 & $1,967,600$ & 301,761 & $-29 \%$ & $-44 \%$ & $-31 \%$ \\
FF2 & 600,000 & 86,010 & 840,270 & 128,359 & $-29 \%$ & $-33 \%$ & $-29 \%$ \\
FF3 & 242,000 & 41,600 & 336,880 & 57,788 & $-28 \%$ & $-28 \%$ & $-28 \%$ \\
FF4 & 342,000 & 48,690 & 480,560 & 69,944 & $-29 \%$ & $-30 \%$ & $-29 \%$ \\
FF5 & 162,000 & 26,600 & 425,140 & 40,705 & $-62 \%$ & $-35 \%$ & $-60 \%$ \\
FF6 & 78,000 & 9,003 & 59,164 & 11,218 & $32 \%$ & $-20 \%$ & $24 \%$ \\
FF7 & 72,500 & 7,192 & 49,763 & 9,087 & $46 \%$ & $-21 \%$ & $35 \%$ \\
FF8 & 67,000 & 7,129 & 49,418 & 9,348 & $36 \%$ & $-24 \%$ & $26 \%$ \\
FF9 & 57,000 & 5,981 & 39,741 & 7,244 & $43 \%$ & $-17 \%$ & $34 \%$ \\
\hline
\end{tabular}

In this work, among the three methodologies covered, two of them separate the total life between crack nucleation life, $N_{i}$, and crack propagation life, $N_{p}$. However, in one of these approaches, the wear effect is considered to compute $N_{i}$. Table 3 presents the results of life estimates for these two methodologies and compares the difference in the estimate of $N_{i}$ and $N_{p}$. It is noted that the inclusion of wear has increased the estimated total life for some tests while for others there is a reduction. As previously mentioned, the inclusion of wear in the analysis generated a reduction in the estimated values of $N_{p}$ for all tests, with an average reduction of $-28 \%$. However, the tests with shorter lives (FF6 to FF9) had an average increase in $N_{i}$ of $39 \%$, while the other tests (FF1 to FF5) showed an average reduction of $-35.4 \%$. A similar result is seen when assessing total life.

The variation in energy dissipated at the contact surface can be used to explain why the inclusion of surface wear has brought clear benefits for some cases and others not. Ruiz et al. [33] proposed two damage parameters for the fretting fatigue problem. One of these parameters, the fretting wear parameter, basically calculates the amount of frictional work at the contact interface and can be written as $K_{1}=\tau \times \delta$. The second parameter is called fretting fatigue parameter and can be written as $K_{2}=\tau \times \delta \times \sigma_{x}$. The concept of cumulative dissipated energy, $E_{d}$, introduced by [32] is the summation of parameter $K_{1}$ in each increment of the time during one full cyclic loading condition.

With this in mind, it can be said that the higher the value of $K_{1}$ and con- 
sequently $E_{d}$, the greater will be the effect of wear in the failure mode of the material. Figure 17 shows that the tests FF6 to FF9 are the tests with the highest values of dissipated energy. The hypothesis that tests with a higher $E_{d}$ values would be more affected by wear is confirmed when we verify the results in Figure 22. In this figure, the maximum energy dissipated is related to the error in life assessment of each test for each numerical model proposed. This error is the subtraction between the experimental life and the life estimated numerically. The tests that presented the highest values of $E_{d}$ had fewer errors in the life prediction when the wear is taken into account. It is also noted that for $E_{d}<0.2 \mu J / \mathrm{mm}^{2}$, in terms of life assessment there is no need for computed wear, as the results are very close to the results obtained by the conventional method where the processing cost is much lower.

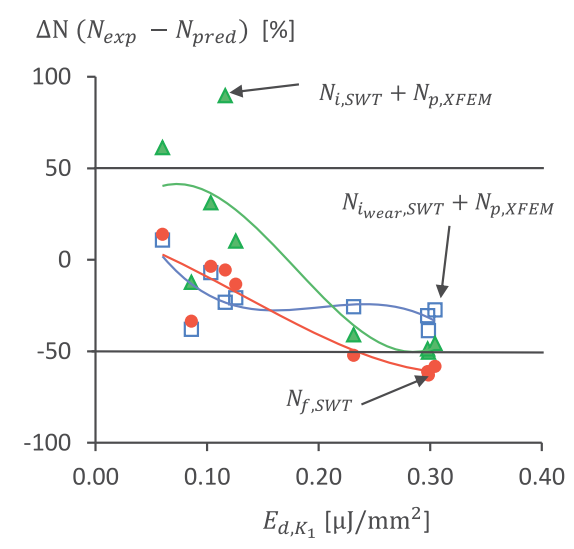

Figure 22: Correlation between maximum energy dissipated with life prediction error.

Parameter $K_{1}$ does not consider the effects of tangential stress on the fatigue specimen or the normal load on the pad. The inclusion of the load effect can be done by normalizing parameter $K_{2}$ with the maximum normal pressure, $p_{0}$, as shown in Figure 23. Note that considering the normalized $K_{2}$ parameter, the observed behavior is similar to that in Figure 22. But now it can be said that for dissipated energy values $E_{d}<0.04 \mu \mathrm{J} / \mathrm{mm}^{2}$ there is no need to compute the surface wear.

\section{Conclusions}

This research aimed to propose a numerical methodology to estimate the life of components subjected to fretting fatigue including the effects of surface wear and crack propagation. To calculate the wear, Archard's law was applied and the crack modeling was performed using the XFEM method. The conclusions are drawn as follows: 


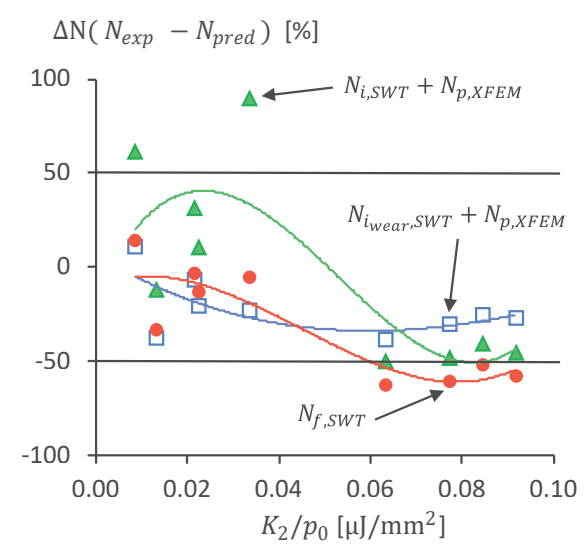

Figure 23: Correlation between maximum energy dissipated normalized with life prediction error.

(1) Among the methods proposed to predict the crack trajectory, the $S W T_{L_{0}}$ method stood out, obtaining a better crack trajectory than traditional methods like $M T S, K_{I I}=0$, and $M E R R$.

(2) A comparative study between the parameters $S W T$ and $F S$, without the presence of wear, showed that $S W T$ presents more conservative results than $F S$ for the material studied. Therefore, subsequent analyses including the wear effect were performed only with the $S W T$ parameter.

(3) In terms of life assessment, the two simplest methodologies performed well for long lives, over $2 \times 10^{5}$ cycles. However, for short lives, the predictions were outside the scatter band 2 . The proposed methodology including wear effect and crack propagation presented more conservative and accurate results than the other methods. All the results fell within the scatter band 2, with an error between $11 \%$ and $-39 \%$.

(4) It is important to note that, because of the wear effect inclusion, $N_{p}$ had an average reduction of $-28 \%$, in which all tests had a similar result. However, the tests with shorter lives (FF6 to FF9) had an average increase in $N_{i}$ of 39 $\%$, while the other tests (FF1 to FF5) showed an average reduction of $-35.4 \%$. A similar result is seen when assessing total life.

(5) The analysis of the maximum friction energy dissipated during a fretting cycle showed that the wear effect was noticeably greater in tests with $E_{d}>$ $0.2 \mu \mathrm{J} / \mathrm{mm}^{2}$. In these cases, this phenomenon plays a very important role in the failure mechanism of the material.

(6) In an attempt to generalize the results to the use of other alloys or loading configurations the Ruiz's parameter $K_{2}$ was normalized by the pressure. This way all the main loads that influence the fretting fatigue problem are included in the analysis. Therefore, it can be said that for an energy dissipation greater than $0.04 \mu \mathrm{J} / \mathrm{mm}^{2}$ it is important to include the effects of wear. 


\section{Acknowledgements}

The authors would like to acknowledge the financial support of TBE (Transmissoras Brasileira de Energia) in the context of the project entitled "Fadiga de Cabos de Alumínio Liga (CAL) 1120 e 6201: estudo comparativo, efeito de grampos AGS e de emendas pré-formadas". This project has been developed within the Programme of Research and Technological Development from the Electricity Energy Sector regulated by ANEEL. 


\section{References}

[1] R. Waterhouse, Fretting wear, Wear 100 (1-3) (1984) 107-118.

[2] R. . Waterhouse, Fretting fatigue, International materials reviews 37 (1) (1992) 77-98.

[3] O. Vingsbo, S. Söderberg, On fretting maps, Wear 126 (2) (1988) 131-147.

[4] N. A. Bhatti, M. A. Wahab, Fretting fatigue crack nucleation: a review, Tribology International 121 (2018) 121-138.

[5] A. Fantetti, L. Tamatam, M. Volvert, I. Lawal, L. Liu, L. Salles, M. Brake, C. Schwingshackl, D. Nowell, The impact of fretting wear on structural dynamics: Experiment and simulation, Tribology International 138 (2019) $111-124$.

[6] J. Archard, Contact and rubbing of flat surfaces, Journal of applied physics 24 (8) (1953) 981-988.

[7] J. Ding, S. Leen, I. McColl, The effect of slip regime on fretting wearinduced stress evolution, International journal of fatigue 26 (5) (2004) 521531.

[8] R. Cardoso, T. Doca, D. Néron, S. Pommier, J. Araújo, Wear numerical assessment for partial slip fretting fatigue conditions, Tribology International 136 (2019) 508-523.

[9] A. L. Pinto, R. Cardoso, R. Talemi, J. A. Araújo, Fretting fatigue under variable amplitude loading considering partial and gross slip regimes: Numerical analysis, Tribology International 146 (2020) 106199.

[10] R. Hojjati-Talemi, M. A. Wahab, J. De Pauw, P. De Baets, Prediction of fretting fatigue crack initiation and propagation lifetime for cylindrical contact configuration, Tribology International 76 (2014) 73-91.

[11] R. Smith, P. Watson, T. Topper, A stress-strain parameter for the fatigue of metals, Journal of Materials 5 (4) (1970) 767-778.

[12] K. Smith, A stress-strain function for the fatigue of metals, Journal of materials 5 (1970) 767-778.

[13] A. Fatemi, D. F. Socie, A critical plane approach to multiaxial fatigue damage including out-of-phase loading, Fatigue \& Fracture of Engineering Materials \& Structures 11 (3) (1988) 149-165.

[14] D. Socie, Critical plane approaches for multiaxial fatigue damage assessment, in: Advances in multiaxial fatigue, ASTM International, 1993.

[15] R. Peterson, Methods of correlating data from fatigue tests of stress concentration specimens, Stephen Timoshenko Anniversary Volume (1938) 179. 
[16] H. Neuber, Forschg ing-wes 7 (1936).

[17] J. M. Whitney, R. J. Nuismer, Stress fracture criteria for laminated composites containing stress concentrations, Journal of composite materials 8 (3) (1974) 253-265.

[18] K. Tanaka, Engineering formulae for fatigue strength reduction due to crack-like notches, International Journal of Fracture 22 (2) (1983) R39R46.

[19] D. Taylor, G. Wang, The validation of some methods of notch fatigue analysis, Fatigue \& fracture of engineering materials \& structures (Print) 23 (5) (2000) 387-394.

[20] J. Araújo, L. Susmel, M. Pires, F. Castro, A multiaxial stress-based critical distance methodology to estimate fretting fatigue life, Tribology International 108 (2017) 2-6.

[21] F. Erdogan, G. Sih, On the crack extension in plates under plane loading and transverse shear (1963).

[22] K. Hayashi, S. Nemat-Nasser, Energy-release rate and crack kinking under combined loading (1981).

[23] B. Cotterell, J. Rice, Slightly curved or kinked cracks, International journal of fracture 16 (2) (1980) 155-169.

[24] C. Navarro, J. Vázquez, J. Domínguez, Nucleation and early crack path in fretting fatigue, International Journal of fatigue 100 (2017) 602-610.

[25] I. McColl, J. Ding, S. Leen, Finite element simulation and experimental validation of fretting wear, Wear 256 (11-12) (2004) 1114-1127.

[26] S. Fouvry, T. Liskiewicz, P. Kapsa, S. Hannel, E. Sauger, An energy description of wear mechanisms and its applications to oscillating sliding contacts, Wear 255 (1-6) (2003) 287-298.

[27] T. Doca, F. A. Pires, Finite element modeling of wear using the dissipated energy method coupled with a dual mortar contact formulation, Computers \& Structures 191 (2017) 62-79.

[28] A. Palmgren, Die lebensdauer von kugellargern, Zeitshrift des Vereines Duetsher Ingenieure 68 (4) (1924) 339.

[29] M. Miner, J. appl. mech., Cumulative damage in fatigue 12 (1945) 159.

[30] J. Newman Jr, E. P. Phillips, M. Swain, Fatigue-life prediction methodology using small-crack theory, International Journal of fatigue 21 (2) (1999) 109119. 
[31] A. Ashwin, R. H. Lakshman, C. C. Swaroop, M. Vignesh, R. V. Vignesh, R. Padmanaban, Predicting the wear rate of aluminum alloy aa2024-t351 using hybrid linear function and radial basis function, in: IOP Conference Series: Materials Science and Engineering, Vol. 561, IOP Publishing, 2019, p. 012046.

[32] H. Mohrbacher, J.-P. Celis, J. Roos, Laboratory testing of displacement and load induced fretting, Tribology international 28 (5) (1995) 269-278.

[33] C. Ruiz, P. Boddington, K. Chen, An investigation of fatigue and fretting in a dovetail joint, Experimental mechanics 24 (3) (1984) 208-217. 


\section{Appendix A. Moving node technique applied to wear modeling}

In this appendix, one aims to give some details about the numerical implementation of the wear modeling strategy considered in this work. In this setting, Figure A.24 displays a flowchart illustrating the FE-based wear model coupled with the moving node technique. Herein, the main Python script manages all the process which consists of the simulation of each fretting cycle $i$ followed by the contact surfaces updating, where contact nodes are vertically moved according to Eq. (8) or (??) depending on the wear model used. As can be seen in Figure A.24, instead of creating a new CAE file and consequently a new mesh, it is used the input file to run the simulation. This way there is no necessity to create another mesh.

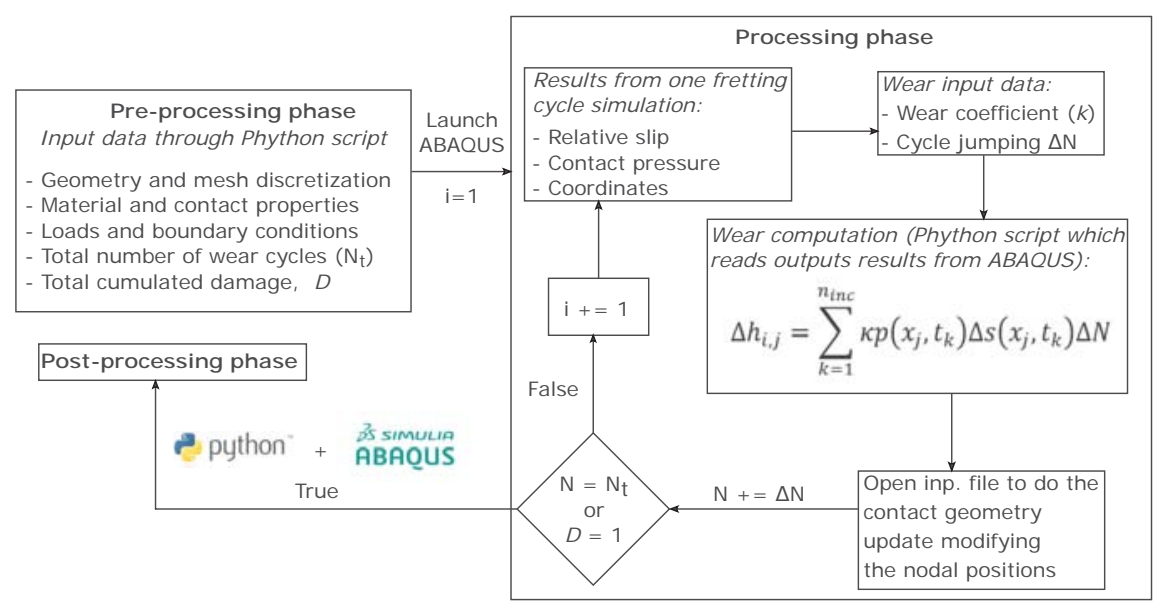

Figure A.24: FE-based model for wear analysis using the moving node technique.

Note that although surface wear is considered in both specimens and pad, the damage generated in the material is computed only in the specimen, as shown in Figure A.25. Once the TCD is here used to account for geometric features, damages computations are considered for all elements but only the damage on points at least $\mathrm{L}$ distant from the contact surface is used as a stop criterion for the simulation, red dots on Figure A.25. 


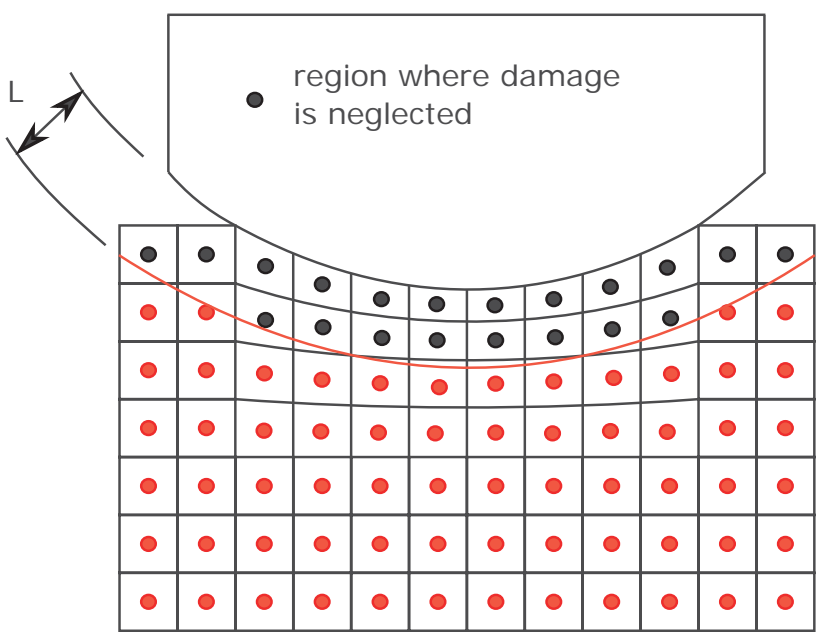

region where damage

is considered

Figure A.25: Damage accumulation procedure considering wear.

Appendix B. Results of fretting fatigue tests taking wear into account

In this appendix, one aims to give detailed results of all fretting fatigue tests including wear and crack propagation. From the availability of these results, it is possible to observe in greater detail the wear profiles and stress distribution in each test. It is clear that, regardless of the worn and stress profile obtained, the crack path tends to always be the same. Also, the results presented in this Appendix will be useful for future researchers to compare with different models or even try to reproduce the same results with the method proposed in this work. 
a)

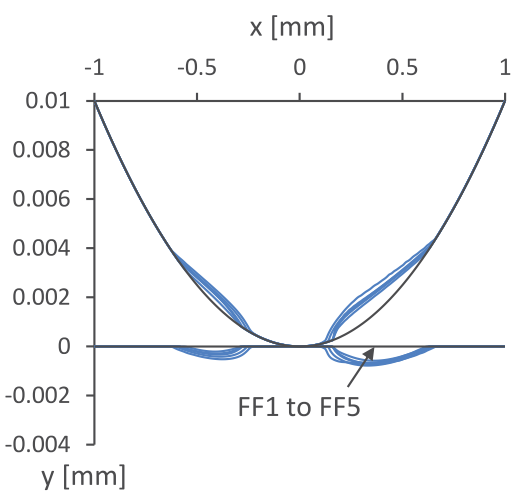

c)

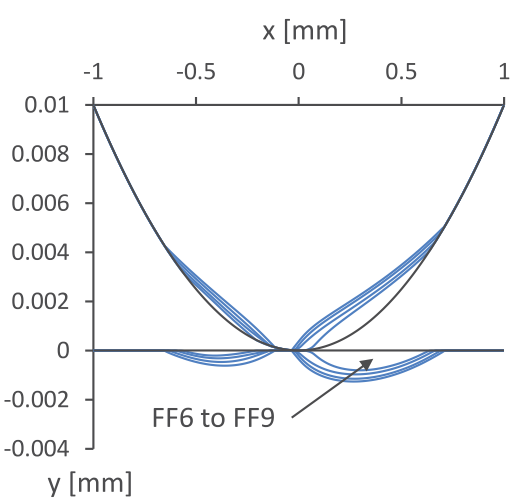

b)

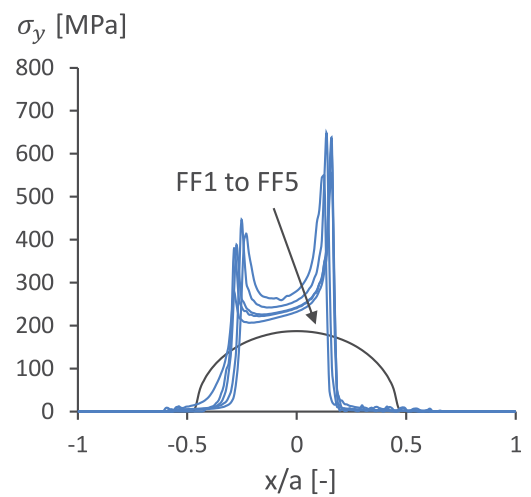

d)

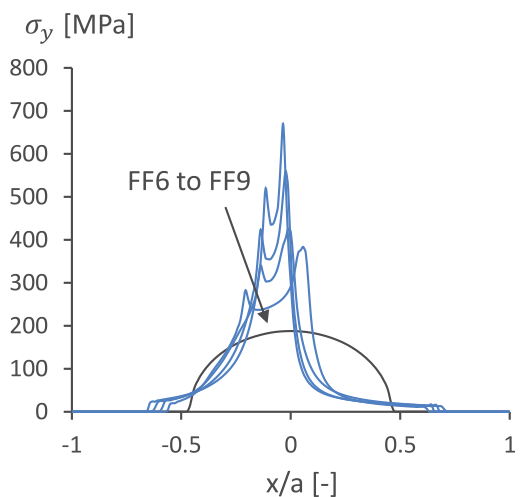

Figure B.26: Comparison between surfaces worn from FF1 to FF5 (a) and from FF6 to FF9 tests (c), normal pressure distribution from FF1 to FF5 (b), and from FF6 to FF9 tests (d). 
a)

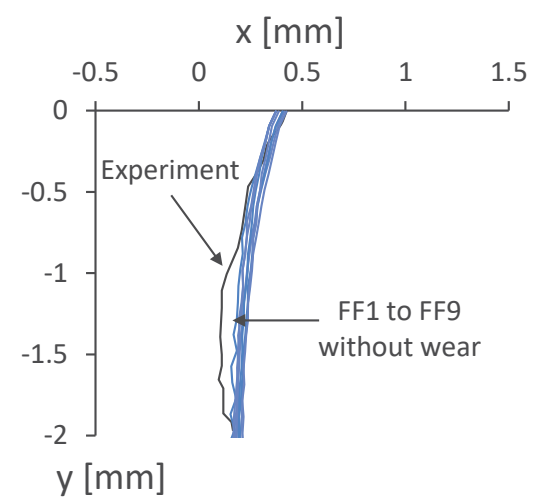

b)

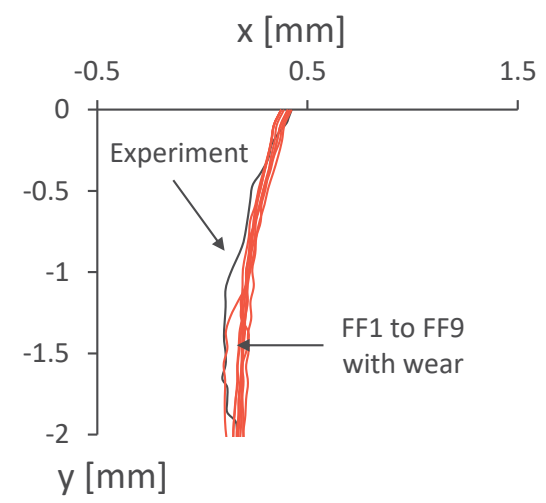

Figure B.27: Crack path without wear (a) and with wear effects (b).

a)

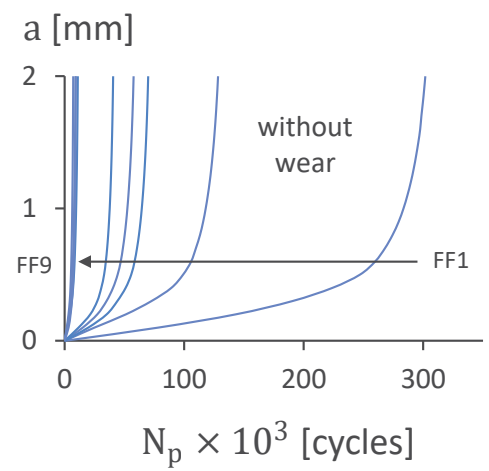

b)

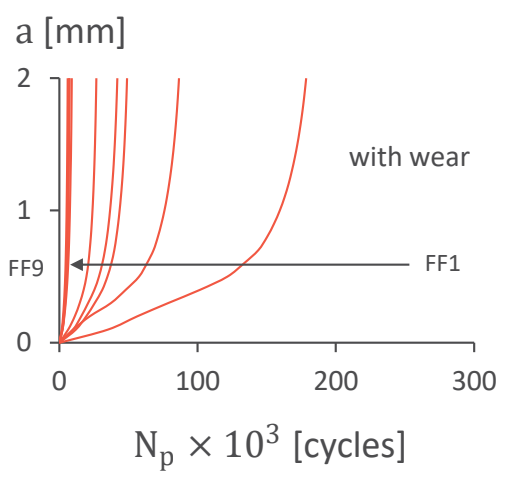

Figure B.28: Crack propagation life without wear (a) and with wear effects (b) 